
\title{
BReserch Soute \\ Probing the Nature of Code Mixing and Code Switching From Amharic to Awigni and Its Influence on the Indigenous Language-Awigni
}

Adugna Techane ( $\sim$ adugnayitayish@gmail.com )

Injibara University

\section{Research Article}

Keywords: Code Mixing, Code Switching, Amharic Language, Awigni Language

Posted Date: March 7th, 2022

DOI: https://doi.org/10.21203/rs.3.rs-1414611/v1

License: @ (i) This work is licensed under a Creative Commons Attribution 4.0 International License. Read Full License 


\section{Abstract}

The main purpose of this study was to explore the nature of code mixing and code switching from Amharic to Awigni and its influence on the indigenous language-Awigni at Injibara town, Awi zone, Ethiopia. The subjects of the study were from the woredas' educational bureau, cultural and tourism bureau and public schools located at the town. So as to achieve this goal, a mixed research design was employed. Thirty two respondents were selected from the woredas' educational bureau, cultural and tourism bureau and public schools through using comprehensive sampling technique were as the participants of the study. Questionnaire, interview, observation, and FGD were utilized to gather data. The findings indicated that different aspects of Awi language is affected due to the influence of Amharic language. Basically, its morphology has been affected. The results also revealed that in the case between Amharic and awigni, there are four basic causes to mix and switch. These include boarder proximity, religious activities, and historical relationship and trade activities. Moreover, speakers mix and switch codes from Amharic due to different relations with Amharic speakers. Finally, it is recommended that collecting the original Awigni language words and sounds from elders should be the task to everyone to save the language.

\section{Introduction}

Language is the human use of spoken or written words as a communication system. It is the speech of a country, region, or group of people including its vocabulary, syntax and grammar. It is an instrument or a system of communication with its own set of codes. When we say language is an instrument for communication, it has its own influence on the speech community and the speech community has its own impact on the language they speak. This situation leads to the study of the interaction between language and society which can be seen under sociolinguistics. Fatiman (2013) explains this concept as society impinges on language and language impinges on society. The interdependency of these two entities in language and society lead to the study of sociolinguistics.

When different speech communities are living together, there will be a situation of mixing and switching codes from other languages around them. A code may be a language, or a variety or style of a language. In this study, code will be taken as a verbal component that can be as small as a morpheme or as comprehensive and complex as the entire system of language.

Scholars like Amuda (2009), Atoye (2005), Belly (2011) and Hymes (1974) have attempted to define codeswitching as a common term for alternative use of two or more languages, varieties of a language or even speech styles while Bokamba (2004) defines both concepts as: code-switching is the mixing of words, phrases and sentences from two distinct grammatical (sub) systems across sentence boundaries within the same speech event... code-mixing is the embedding of various linguistic units such as affixes (bound morphemes), words (unbound morphemes), phrases and clauses from a co-operative activity where the participants, in order to infer what is intended, must reconcile what they hear with what they understand.

From this, one can possible to say that the term code mixing emphasizes hybridization, and the term codeswitching emphasizes movement from one language to another. Mixing and switching probably occur to some extent in the speech of all bilinguals so that there is a sense in which a person capable of using two languages, 
$A$ and $B$, has three systems available for use: $A, B$, and $C$ (a range of hybrid forms that can be used with comparable bilinguals but not with monolingual speakers of $\mathrm{A}$ or $\mathrm{B}$ ).

Code mixing and code switching can be appeared as tag-switching in which tags and certain set phrases in one language are inserted into an utterance otherwise in another, intra-sentential switching in which switches occur within a clause or sentence boundary, inter sentential switching, in which a change of language occurs at a clause or sentence boundary, where each clause or sentence is in one language or the other, and intra-word switching in which a change occurs within a word boundary.

Code mixing and code switching of a certain language is not a casual phenomenon. It has its own reasons. According to Peter (2017), there may be many reasons that people mix and switch codes. Sometimes it may be an index of membership in bilingual and multilingual societies. In other case, switching and mixing is not simply to reflect social situation rather it is a means to create social situation.

The multilingual nature of a country or a speech community as well as multilingual or bilingual ability of individuals can lead that speech community or individual to mix and switch codes between languages. Fatiman (2013) in his study says that the nature of a country and some individuals' bilingual and multilingual competence and the inter language relationship between languages leads to code mixing and code switching in conversation, discourse and communicative competence. Thus, this mixing and switching code can facilitate communication.

Although code mixing and code switching is functional to facilitate communication, it has its own influence on the indigenous language. Sometimes it creates new styles of communication especially for those people who are monolingual in that speech community. Regarding this, Dr. Stagvroula Tsiplakou (2007) argues that any attempt to code switching and code mixing inevitably stumbles across a serious of theoretical as well as practical problems on all aspects of linguistics especially on matrix of the base language.

Most of the time code mixing and code switching appears within bilingual and multilingual speech communities. Thus, Awi zone is one of the multilingual regions of Ethiopia. Amharic, Awigni and Kunfel are some of the languages which are spoken in the Zone. Due to this multilingual nature of the zone, there is a high range of mixing and switching of codes between the languages in the region. From these languages, code switching and code mixing is usual between Awigni and Amharic. Besides, there are no studies conducted to examine the zones, functions and effects of mixing and switching codes between the languages. It is worthwhile, therefore, this study sought to explore the nature of code mixing and code switching from Amharic to Awigni and its influence on the indigenous Language-Awigni. The study tried to seek answers to the following questions: RQ1. Why Awigni language speakers mix and switch codes from Amharic language? RQ2. How they apply code mixing and code switching from Amharic? RQ3. What is its effect on the native languageAwigni?

\section{Methodology}

In this present study, a mixed method research design which applies quantitative and qualitative methods of data collection was employed. This is because it is applicable to obtain valuable information about the nature of code mixing and code switching from Amharic to Awigni and its influence on the indigenous language- 
Awigni. Mixed research design enables the researchers to come up with what has happened or what is happening (Kothari, 2004). The rationale why a mixed approach was employed is that it enabled the researchers to see the issue under study both from qualitative, and quantitative perspective. Also, the nature of the problem and the research objectives invited the researchers to use this research method.

\section{Sources of Data}

So as to collect the required data, the study used both primary and secondary data sources. It would employ questionnaire, interview, and observation and focused group discussion methods to collect a primary data. Written documents such as letters from different sectors and textbooks in Awigni language would be taken as a secondary data sources.

\section{Research Site and Study Participants}

The study was conducted at Injibara town, which is located in Awi Zone, Amhara, Ethiopia in 2020/2021 GC. It was selected purposively for its ease of accessibility of information for the researchers. A research participants are the units of analysis as they are the sources from which research data are being collected (Higson Smith, 2000). Thus, the data analysis should reflect an accurate picture of the research participants. In light of this, the analysis and the general discussion of this study revolved around at the respondents who were able to speak both Awigni and Amharic languages. Accordingly, the subjects of the study were from the woredas' educational bureau, cultural and tourism bureau and public schools located in this town. School directors, managers from the woredas' education and cultural bureaus, and other individual respondents who are able to speak both Awigni and Amharic languages were selected. The total number of respondents' population in the selected sites (area of the study) were $32(M=18, F=14)$. Those were selected for this study through using comprehensive sampling technique as they are available in the sites. This is because a number of participants were manageable to take the sample as comprehensive.

\section{Instruments}

Four instruments were employed to investigate exploring the nature of code mixing and code switching from Amharic to Awigni and its influence on the indigenous language-Awigni. The instruments were questionnaire, interview, classroom observation and FGD for both directors and administrators and managers those who were selected from woredas' educational bureaus, cultural and tourism bureaus and schools found in the town. Using these instruments, quantitative and qualitative data were collected. Thus, to obtain the necessary data from the subjects, questionnaire would be designed and distributed for 32 respondents who can understand either Amharic or English well in addition to Wigni. The questionnaire contained both open and close ended questions. From these 32 respondents, 24 respondents gave their responses and the remaining 8 respondents didn't give the questionnaire back. So as to gather additional reliable and acceptable information from the subjects, interview was used. Therefore, school directors found in the town and administrators from the selected sectors would be interviewed.

Furthermore, observation was the other way of obtaining data through observing the actual speech situation found in the study areas. Therefore, the researchers had an observation for sixty days within four terms in the study areas. Finally, the researchers used FGDs so as to gather detailed accounts of the issues under 
discussion. Hence, in focused group discussion, informants would be given a certain title to discuss on. Both observations and focus group discussion would be held using a structured observation check list. They had been activated by using a translator particularly, around market places and schools to assess the unconscious mixing and switching of codes from Amharic to Awigni.

\section{Data Analysis}

After collecting data from different sources, it would be analyzed using both a qualitative and quantitative methods. Data gathered through questionnaire and interview would be tabulated and interpreted quantitatively, whereas data gathered through observation and from written documents would be analyzed qualitatively. Furthermore, the occurrence of code mixing and code switching would be counted and classified into three categories whether it is applied in the form of a) insertion b) alternation and c) congruent lexicalization. Upon this classification and interpretation, its results would be analyzed and compared to draw conclusions and recommendation.

\section{Findings}

As stated earlier, the study is mainly concerned with identifying the influence of Amharic language on Awigni language due to code mixing and code switching. Most scholars argue that code mixing and code switching between languages can facilitate communication and strengthen the relationship between speech communities. However, from linguistics point of view, it affects the host language. This becomes very difficult especially if the host language speakers replace sounds, words and phrases of their own language with the foreign one. The case has been reflected between Awigni and Amharic. Because of the influence of Amharic, Awigni speakers loose many words, some sounds and almost all of their numbers. Though there is difference in using Amharic words and phrases between dialects of Awigni, majority of Awigni speakers are affected in using Amharic instead of their own.

Table 1: Causes of Mixing and Switching Language Codes from Amharic to Awigni, and respondents' response for social factors led them to mix and switch codes from Amharic to Awigni language.

\begin{tabular}{|c|c|c|c|c|c|}
\hline \multirow[b]{2}{*}{ Question } & \multicolumn{4}{|c|}{ No of Respondents } & \multirow[b]{2}{*}{$\begin{array}{l}\text { if any } \\
\text { other } \\
\text { factors }\end{array}$} \\
\hline & $\begin{array}{l}\text { boarder } \\
\text { proximity }\end{array}$ & $\begin{array}{l}\text { marriage } \\
\text { activities }\end{array}$ & $\begin{array}{l}\text { religious } \\
\text { activities }\end{array}$ & $\begin{array}{l}\text { trade } \\
\text { activities }\end{array}$ & \\
\hline $\begin{array}{l}\text { What social factors lead you to mix and switch } \\
\text { codes from Amharic to Awigni language }\end{array}$ & 5 & 0 & 7 & 3 & 9 \\
\hline
\end{tabular}

As stated in Table 1, one can understand that respondents on factors that leads them to switch and mix codes from Amharic to their language. Based on their response, religion and historical relationship are major causes that contain 5 or $29.1 \%$ and 9 or $37.5 \%$ of the total respondents respectively. The remaining five respondents or $20.8 \%$ and 3 or $13.6 \%$ said boarder proximity and trade activities are causes to mix and switch codes from Amharic. 
Accordingly, there are four basic causes to mix and switch codes in these languages. These are boarder proximity, religious activities, and historical relationship and trade activities.

It is common that, in sociolinguistics, there are different factors which lead a speech community to mix and switch codes between different language codes. Most probably, these factors replay on either of the two basic situations. These are either multi-lingual factors of a society or different relationships between different speech communities. Many linguists argue that mixing and switching codes due to multi-lingual factors of a society is more common than mixing and switching codes of different languages due to different relations and the second one affects the host language.

In case of Awigni language, speakers mix and switch codes from Amharic due to different relations with Amharic speakers. Regarding to factors what make respondents to mix and switch from Amharic language, they responded that boarder proximity, religion and trade activities with Amharic speakers are the major ones. Accordingly, it can be discussed as follows.

\subsection{Religion}

The second factor to mix and switch codes from Amharic to Awigni is religion. In this case, religion by itself cannot be a cause, rather when Awigni speakers learn Orthodox religion, since it was taken in Amharic, they mix and switch many Amharic codes and use in their mother tongue language. Due to this, some Awigni words are replaced by Amharic version.

\subsection{Trade Activities}

It is known that, in a globalized world, people of the world have trade exchanges between neighboring countries and even from corners. The same is true between Amharas and Agew people. Of course, trade by itself cannot be the cause for language distraction, however, during their transaction people normally do not only exchange goods and services, and rather they also exchange ideas since they communicate through language. Furthermore, most products are named by the producers' language-Amharic. Therefore, they mix and switch codes to understand each other.

As respondents, trade activity between Amhara and Agew has a long time history. Due this trade transaction, the exchange of language codes especially taking Amharic codes to their language is common.

\subsection{Proximity}

Proximity between Amharas and Agews is another factor for the situation of mixing - switching codes between the languages. As the respondents mention, since they are close, many Amharas come to the areas where Agew people live including Injibra town and vice versa. They added that the influence of Amharic speakers on Awigni speakers is relatively less at the areas relatively far from Gojjam.

Table 2: Respondents' response to what level of linguistic elements they mix and switch codes from Amharic language 


\begin{tabular}{|l|lllll|}
\hline Question & $X$ & $Y$ & W & Q & Z \\
\hline To what level of linguistic elements do you take from Amharic language? & 6 & 7 & 9 & 2 & 0 \\
\hline
\end{tabular}

$\{$ Key: $\mathrm{X}=$ Codes at Phone Level, $\mathrm{Y}=$ Codes at Morpheme Level, $\mathrm{W}=$ Codes at Word Level, $\mathrm{Q}=$ Codes at Phrase Level, $\mathrm{Z}=$ Codes at Sentence Level\}

The data stated in table 2 disclosed that the linguistic elements taken from Amharic to Awigni. Here, 6 or $25 \%$ of the respondents responded that codes at sound level are taken from Amharic. 7 or $29.1 \%$ of the respondents argued that they took part of a word and attached that part of a word as prefix or suffix. The highest percentage which is $37.5 \%$ or 9 respondents suggested that taking at the word level is more than others. Though the respondents in the questionnaire responded this way, as respondents in the FGD and interview discussed, almost the three levels that means at phoneme level, at morpheme level and at word level are highly practiced little at phrase level and almost no at sentence level. For further elaboration, we can look at the following desiccations.

As most of the respondents responded, in earlier times, Awigni speakers mix and switch codes from Amharic to Awigni in their speech. At this time, the mix reaches to the writing level. As it has been known, the writing system in Awigni language is a recent phenomenon. That is why the mixing and switching rate is still in spoken part of the languages.

Table 3: Respondents Response on how do they employ these levels of linguistic elements that they have taken from Amharic?

\begin{tabular}{|llll|}
\hline \multicolumn{3}{c}{ Question } & \multicolumn{3}{c|}{ No of Respondents } \\
\cline { 2 - 4 } & $\begin{array}{l}\text { Take a } \\
\text { morpheme and } \\
\text { attach that } \\
\text { morpheme as } \\
\text { prefix, infix or } \\
\text { suffix }\end{array}$ & $\begin{array}{l}\text { Take the alternative words } \\
\text { of Arabic to the already } \\
\text { existed words of Berta } \\
\text { language and replace } \\
\text { them. }\end{array}$ & $\begin{array}{l}\text { Simply take Amharic words } \\
\text { with some modifications } \\
\text { because there are no their } \\
\text { congruent lexicon in Berta. }\end{array}$ \\
\hline $\begin{array}{l}\text { How do you employ } \\
\text { these levels of } \\
\text { linguistic elements that } \\
\text { you have taken from } \\
\text { Amharic? }\end{array}$ & 9 & 11 & 4 \\
\hline
\end{tabular}

The above table disclosed the way that how Awigni speakers mix and switch codes of Amharic. From here, it is possible to determine how Awigni speakers exercise the codes that they took from Amharic. As it is shown in table 3,11 respondents or $45.8 \%$ and 9 or $37.5 \%$ of the respondents argued that the two linguistic pillars (i.e. replacement and insertion) are highly practiced. Whereas the remaining 4 respondents or $16.7 \%$ said they take some words with some internal modifications. The following justifications convinced the practice.

Hence, this part revisits how Awigni people mixes and switch codes of Amharic to their language. From linguistics' point of view, when there is a situation of mixing and switching codes between languages, it can be employed in 1, insertion 2, replacement 3, congruent lexicalization or with modification. According to the information obtained from respondents, which has been collected through FGD and interview, except congruent 
lexicalization, all pillars of mixing codes which are listed above are involved between Bertha and Amharic. As the respondents' response, replacement and insertion are very common.

\subsection{Replacement}

Replacement is when a speech community mixes and switches codes of another language by replacing their original words with others language words. It is not related to borrowing. This is because borrowing is the addition of vocabulary to the host language without affecting the original words of their own language. On the other hand, replacement due to code-mixing is losing the original words of the host language and replacing them with the new words from the new language code. As it can been seen from the respondents' response, many Awigni words are replaced by Amharic words.

If a speech community replaces a word and if they are not aware of whether they are mixing and replacing, it is difficult for the language. This is because if the speakers are unconscious about the replacement, they can't remember their original words and take the new words as their own. Here, Awigni speakers are not aware about the replacement of most of their words by Amharic words.

\subsection{Insertion}

In linguistic, insertion is the way of taking a word or part of a word from one language and insert it to a language. The process of inserting can be employed by taking part of a code from one language to another as a prefix, suffix, and infix or as a full flagged word. Basically, insertion is taking a code at morpheme level.

In case of Awigni, insertion is very common. Awigni speakers take a prefix and insert it to their common word formation process. As many of respondents have been discussed, it is very common to take 'al- which is the Amharic version of the definite article the as a prefix of Awigni particularly, with Amharic loan words. Now a days, this prefix becomes very common even before personal names.

Table 4: Respondents response whether or not they know any alphabets of Awigni taken from Amharic

\begin{tabular}{|lcc|}
\hline Question & \multicolumn{2}{c|}{ No of Respondents } \\
\cline { 2 - 3 } & Yes & No \\
\hline Do you know any alphabets of Awgni taken from Amharic? & 0 & 24 \\
\hline
\end{tabular}

As the data witnesses in table 4, it is possible to say that $100 \%$ of respondents know that there are no alphabets of Awgni language taken from Amharic. In line with this, some of the respondents responded that though there are no alphabets that are directly taken from Amharic to Awigni, there are some sounds that are taken with Arabic loan words.

Table 5: Respondents response regarding the reasons for their mixing and switching of codes between the languages 


\begin{tabular}{|c|c|c|c|c|c|c|}
\hline \multirow[b]{2}{*}{ Question } & \multicolumn{3}{|c|}{ No of Respondents } & \multirow[b]{2}{*}{$\begin{array}{l}\text { to cover up } \\
\text { taboo } \\
\text { expressions }\end{array}$} & \multirow[b]{2}{*}{$\begin{array}{l}\text { Because } \\
\text { you think } \\
\text { that } \\
\text { Arabic is } \\
\text { more } \\
\text { expressive }\end{array}$} & \multirow[b]{2}{*}{$\begin{array}{l}\text { if any } \\
\text { other } \\
\text { factors }\end{array}$} \\
\hline & $\begin{array}{l}\text { as a matter of } \\
\text { habit(unconsciously) }\end{array}$ & $\begin{array}{l}\text { To } \\
\text { strength } \\
\text { your } \\
\text { relation } \\
\text { with } \\
\text { Arabic } \\
\text { speakers }\end{array}$ & $\begin{array}{l}\text { to facilitate } \\
\text { communication } \\
\text { using the } \\
\text { language }\end{array}$ & & & \\
\hline $\begin{array}{l}\text { What is } \\
\text { your } \\
\text { reason for } \\
\text { your } \\
\text { mixing and } \\
\text { switching } \\
\text { of codes } \\
\text { between } \\
\text { the } \\
\text { lanquages? }\end{array}$ & 4 & 6 & 4 & 1 & 9 & \\
\hline
\end{tabular}

As it has been shown in table 5,4 or $16.66 \%$ of the total respondents mix and switch codes from Amharic to Awigni as a matter of habit whereas 6 respondents which covers $25 \%$ of the total population responded that they mix and switch codes to make their relation with Amharas to be better. Besides, 1 respondent or $4.1 \%$ of the respondents answered that they mix codes to facilitate communication and the remaining 9 or $37.5 \%$ of our respondents argued that they mix codes of Amharic to Awigni because they think that Arabic is better than Awigni for the betterment of their expressions.

From the above numerical presentation, one can understand that the two factors enables to strength their relation and their thinking about Amharic language take the lions share. These factors are factors related to the attitudes of Awigni speakers. This attitudinal change is a leading factor for language change.

\section{Conclusion And Recommendations}

\section{Conclusion}

As it has been discussed in the data analysis part, different aspects of Awi language is affected due to the influence of Amharic language. Basically, its morphology has been affected.

There are different causes which lead speakers of two different languages mix and switch codes between them. In the case between Amharic and awigni, there are four basic causes to mix and switch. These include trade activity, geographical proximity and religion. In trade activity, when they exchange goods and services, they took the product with the name in Amharic. As soon as they import the product, they replace the original name of the product with its Amharic name. In the case of religion, since most Agew people are Christians, they should learn Bible which is written in Amharic and Ge'ez. Thus, they become familiar with the language and start to mix with Awigni language. However, religion and language are two different social phenomena. So they don't lose language for religion and religion for language.

Geographical proximity is the other cause. This is because west Gojjam zone and Awi zone are found nearer to each other. So starting from earlier times up to now, most Agew people are going Gojjam and coming back. At 
their movement, they come back with Amharic language and culture.

There are some linguistic criterions or reasons which make code mixing and code switching very sever in these two languages. The first one is the range of this mixing and switching reaches to the level of writing. In linguistics, if mixing rate of languages reaches to writing level or stage, it is called code switching and it leads to language shift. The second one is that many words in Awigni language are replaced by Amharic words and nobody is conscious as they are speaking Amharic.

The other one is the affected group. In a given speech community, if the youth stage group is affected in losing their language in favor of using the others' language code, linguistically, it is difficult for the language. The same is true in Agew. The youth stage of Awigni speakers are highly affected in mixing and switching codes of Amharic language. Therefore, it is difficult to preserve the original Awigni language since most youths are not familiar with the lost Awigni words.

In case of Awi, all these indicators are existed as of the present research. This means Awigni speakers adopt some features of Amharic, adults and parents transfer Amharic language features to their children and historically Amharic has stratal influence on Awigni. The researchers are afraid of these situations would lead to bottom-to-top language death which is language change begins in a low-level environment such as the home.

\section{Recommendations}

Based on the data analyzed in the analysis part, the researchers tried to recommend the following points. As it has been discussed on the analysis and conclusion part, the situation of mixing and switching codes from Amharic to Awigni languages is very sever. It is because it affects different aspects of Awigni language. Therefore, it needs immediate solution before the language is going to be lost. Thus, the following measures should be taken.

First and for most, it is mandatory to search for the original Awigni words. As it has been discussed in data analysis, there are many Awigni words which are lost. So it is better to dig out the original Awigni words which are replaced by Amharic version. The question here could be 'how to search the original Awigni language codes?' the following can help to do so.

One way is using elders as sources of information. This is because as it is tried to explain in the conclusion part, the youth stage of Agew's speech community is highly addicted in mixing and switching of codes from Amharic to Awigni. As most respondents responded that elders are relatively speak the original Awigni. Therefore, collecting the original Awigni language words and sounds from elders should be the first task to save the language.

\section{Declarations}

\section{Acknowledgments}

We would like to say thanks to my friends and research colleagues for their constant encouragement. I express my special thanks to Eyilachew Tamir (PhD) for his genuine support throughout this research work. Finally, our 
thanks go to all the people who have supported us to complete the research work directly or indirectly.

\section{Authors' contributions}

Adugnaw Techane a principal investigator designed the study and collected the data and analyzed and interpreted the data. He wrote the draft of the manuscript so many times and selected the appropriate journal and formatted the manuscript.

Habtamu Anbessie a co-investigator commented and revised the manuscript appropriately and made changes. He also edited the manuscript properly. The two authors read and approved the manuscript together.

\section{Funding}

There were no sources of funding for this research reported in this manuscript

\section{Availability of data and materials}

The datasets of the study are available from the corresponding author on reasonable request

\section{Competing interest}

The authors confirm that they do not have competing interest

\section{References}

1. Amuda, A. (2009). Attitudes to Code Switching: the Case of Yorba and English Odu, New Series No-35.

2. Amsalu, S. (2006). "Data-driven Amharic-English Bilingual Lexicon Acquisition." Proceedings of Language Resources and Evaluation Conference (LREC2006).

3. Baker, M. (2010). "Prepositions" as case morphemes inserted at PF in Amharic." Handout of a talk at the BCGL 5 conference.

4. Atoye, R. (2005). Code Switching, Code Mixing, Borrowing and Linguistic Competence: Cultural Studies in IFE Institutes of Cultural Studies.

5. Belly, R. (2011). Sociolinguistics: Goals, Approaches and Problems. London: B.T. Bats for Ltd.

6. Bokamba, E. (2004). Are They Systematic Constraints on Coode? World English.

7. Clyne, M. (2017). "Constraints on code-switching: how universal are they?" In Li Wei. The Bilingualism Reader. Rutledge.

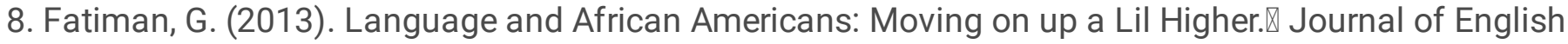
Linguistics. 32(3):189-203.

9. Hymes, D. (1974). The Ethnography in Speaking. In: Gladwin, Anthropology and Man Behavior. Washington.

10. Kothari, C.R. (2004). Research Methodology: Methods and Techniques, Second Revised Edition. New Delhi: New Age International Publishers.

11. Peter, R. (2013). Semitic Languages: Harari. Madison AVC. New York. 
12. Romaine, A., Suzanne, Z., and Braj, K. (2015). "Code-mixing and code-switching." The Oxford Companion to the English Language. Oxford University Press.

13. Stagrovroula, T. (2013). Code Switching and Code Mixing Between Related Varieties. Nicisia:Cyprus University.

14. Wardhaugh, R. (2002). "Pidgins and Creoles." In An Introduction to Sociolinguistics (fourth Ed.). Blackwell. 